\title{
Multi Geochemical Attributes in Lower-Ordovician Dolostones from Tarim Basin: Implications for Genesis of Dolomite and Porosity
}

Zhang You ${ }^{1}$ SHen ANJiAng ${ }^{2}$ Feng ZihuI ${ }^{3}$ ZHENG XINGPING $^{1}$ Zhu MaO ${ }^{1}$ Shao Guanming ${ }^{1}$ Qi Jingshun ${ }^{1}$ ZHANG Junlong $^{1}$

${ }^{1}$ PetroChina Hangzhou Research Institute of Petroleum Geology and zhangshiyouda@126.com

${ }^{2} \mathrm{CNPC}$ Key Laboratory of Carbonate Reservoirs and shenaj @petrochina.com.cn

${ }^{3}$ Exploration and Development Institute of Daqing Oilfield and fengzihui@petrochina.com.cn

Dolomite reservoir in Yingshan Formation of lower Ordovician experienced significant tectonic and diagenesis throughout its long geological history, with strong heterogeneous characteristics. In this paper nearly 1500 samples were collected to reveal genesis of dolomite and reservoir porosity. Firstly, reservoir space types in Yingshan Formation were systematically studied with the use of cores, thin sections, CT scanning and physical properties data. Reservoir space is dominated by the fabric selective reservoir space and mainly exists in fine-coarse crystalline dolomite, with average porosity, $2 \%-4 \%$. Secondly, the distribution of pores has stratification and cycle. The pores mainly developed in the top of upward shallowing sequences, and their formation was related to exposure surface, which was caused by sea-level drop. Huge oxygen, carbon, and strontium isotope elements, trace elements, and surface scanning imaging technology of rare earth elements were analyzed, and the results reflected that dolomitization mainly took place in the shallow-medium burial phase, with the concentrated sea water as the main dolomitization fluid. Some dolomite was partially modified by hydrothermal fluid in the later buried stage, which was demonstrated by silicon isotopic and oxygen isotopic. And the size of crystals was associated with the size of protolith structure and its pore size. The bigger that the protolith structure and pore size was, the coarser the crystalline dolomite would be. This is a good explanation why most reservoir spaces in Yingshan formation mainly developed in the fine-coarse crystalline dolomite. Dolomitization did not produce pores directly. Because of its strong anti-compacting ability, dolomite mainly inherited the early pore, intergranular pore and intercrystalline pore. However, early dolomitization protected most early pores from being compacted. This understanding may be useful in guiding the prediction of ancient dolomite reservoir in Tarim Basin and other areas. 